\title{
Renal tubular function in children and adolescents with Gitelman's syndrome, the hypocalciuric variant of Bartter's syndrome
}

\author{
N. Peters ${ }^{1}$, A. Bettinelli ${ }^{2}$, I. Spicher ${ }^{1}$, E. Basilico ${ }^{2}$, M. G. Metta ${ }^{2}$ and M. G. Bianchetti ${ }^{1}$. \\ ${ }^{1}$ Division of Pediatric Nephrology, University of Berne, Berne, Switzerland; and ${ }^{2}$ Department of Pediatrics II, University of \\ Milan, Italy
}

\begin{abstract}
Renal tubular function was studied in 14 patients with Gitelman's syndrome and 14 control subjects. Apart from the biochemical hallmarks of Gitelman's syndrome, namely alkalaemia, hyperbicarbonataemia, hypokalaemia, hypomagnesaemia (with increased magnesium over creatinine ratio), increased urinary chloride over creatinine ratio, and low urinary calcium over creatinine, the patients were found to have hyperproteinaemia, hypochloraemia, high total plasma calcium concentration, reduced plasma ionized calcium concentration, and high urinary sodium excretion. A statistically significant negative linear relationship between plasma magnesium concentration and magnesium excretion corrected for glomerular filtration was observed in patients. The fractional calcium clearance and the urinary excretion of calcium corrected for glomerular filtration was significantly decreased in patients. In patients the urinary osmolality after overnight water deprivation ranged from 526 to $1067 \mathrm{mmol} / \mathrm{kg}$. Glucosuria and aminoaciduria were similar in patients and controls. The results of the study demonstrate the renal origin of hypomagnesaemia and hypocalciuria in Gitelman's syndrome. The failure to demonstrate hyperaminoaciduria, hyperglucosuria, hyperphosphaturia, hyperuricosuria, and severely impaired urinary concentrating ability provide evidence for a defect residing in the distal convoluted tubule.
\end{abstract}

Key words: Bartter's syndrome; distal convoluted tubule; Gitelman's syndrome; hypocalciuria; hypomagnesaemia; metabolic alkalosis

\section{Introduction}

Hypomagnesaemia, hypocalciuria, hypokalaemic alkalosis, and hyperchloriduria characterize Gitelman's syndrome, a variant of Bartter's syndrome [1-8].

Correspondence and offprint requests to: Dr M. G. Bianchetti Abteilung für Nephrologie, Universitätskinderklinik, Inselspital, CH 3010-Bern, Switzerland.
Patients with this tubulopathy, which is inherited in both dominant and recessive fashions [9], are often asymptomatic, with the exception of muscular weakness and transient episodes of tetany that are sometimes accompanied by abdominal pain, vomiting and fever [1-9].

Since the need for distinguishing between classic Bartter's syndrome and Gitelman's syndrome has been challenged until recently [3-9], information on renal tubular function in this particular disorder is scanty and based on anecdotal reports $[1,2,4-8]$ and a retrospective multicentric inquiry [3]. To address this issue, simple renal tubular function studies were performed in 14 patients with Gitelman's syndrome on follow-up at our centres of Pediatric Nephrology.

\section{Subjects and methods}

Fourteen patients with Gitelman's syndrome ( 7 females and 7 males, aged 10-21 years) entered the study. They had history of frequent tetanic episodes $(n=3)$, muscular weakness $(n=7)$, or both $(n=3)$. Blood pressure, plasma creatinine, urinalysis, and renal ultrasound were normal. Diagnosis of Gitelman's syndrome was based on the presence [3] of normal blood pressure, venous blood $\mathrm{pH}>7.38$, plasma bicarbonate $>28.0 \mathrm{mmol} / 1$, plasma potassium $<3.5 \mathrm{mmol} / 1$, plasma magnesium $<0.75 \mathrm{mmol} / 1$ (by colorimetric assay), molar ratio of urinary calcium over creatinine $<0.100$, urinary chloride over creatinine $>8.42$ [10], urinary magnesium over creatinine $>0.150$ and negative urinary screen for diuretics. The $\mathrm{Z}$ scores for height (from -1.8 to 1.3 ) and body weight (from -1.7 to 1.4 ) were normal.

The 14 patients, who had been without any medication or electrolyte supplementation for at least 5 weeks prior to investigation, attended the outpatient clinic after overnight fasting between 07.00 and $09.00 \mathrm{a} . \mathrm{m}$. They had been instructed to bring a 3-day food record. The patients received a 1.21 tap water loading. After voiding the bladder, a 2-h urine specimen was collected and mid-point blood was taken with minimal stasis and without movement of the forearm.

Packed-cell volume, blood hydrogen ion concentration, blood carbon dioxide tension and plasma ionized calcium concentration were measured in duplicate immediately after blood collection. The remaining samples were immediately stored at $-40^{\circ} \mathrm{C}$ for later determination of creatinine, 
sodium, potassium, chloride, inorganic phosphorus, uric acid, total calcium and magnesium concentration in plasma and urine, and total protein concentration in plasma. The patients were subsequently asked to provide a portion of a first morning urine after overnight water deprivation for determination of osmolality, glucose, protein and amino acids. The aforementioned protocol was applied in a control group of 14 healthy volunteers ( 8 females and 6 males, aged 12 to 20 years).

The study had been approved by the Ethical Committees of the participant centres and informed consent was obtained.

The intake of sodium, calcium and magnesium was assessed from the 3-day food record using dietary charts. Packed-cell volume was assessed by means of a microhaematocrit centrifuge. Blood hydrogen ion concentration, blood carbon dioxide pressure, and plasma ionized calcium concentration were measured using ion-selective electrodes. The blood bicarbonate concentration was calculated using the Henderson-Hasselbalch equation with an acidity exponent of 6.10 and a carbon dioxide solubility coefficient of 0.0301 . The plasma ionized calcium concentration was not corrected for blood hydrogen ion concentration. Total protein, creatinine, potassium, chloride, sodium, inorganic phosphorus, uric acid, total calcium, magnesium, and glucose concentration were measured with an autoanalyser using either ion-selective electrodes or colorimetric assays. The urinary concentration of amino acids was evaluated by column chromathography.

Plasma or urinary electrolytes $\left(\mathrm{P}_{\mathrm{x}}, \mathrm{U}_{\mathrm{x}}\right)$ and creatinine $\left(\mathrm{P}_{\mathrm{Cr}}\right.$, $U_{\mathrm{Cr}}$ ) were used to calculate the corresponding fractional clearance (1) and the urinary excretion corrected for one liter of glomerular filtration rate (GFR) (2) using the following formulae [11]:

$$
\begin{aligned}
& \frac{U_{x} \cdot P_{C r}}{P_{x} \cdot U_{C r}} \\
& \frac{U_{x} \cdot P_{C r}}{U_{C r}}
\end{aligned}
$$

The fractional clearance of calcium was calculated both from total plasma calcium concentration (apparent fractional calcium clearance) as well as from plasma ionized calcium concentration (true fractional calcium clearance). Urinary excretion of electrolytes, amino acids and total protein was also expressed as ratio over creatinine [11]. The tubular threshold for inorganic phosphorus (3) was calculated from plasma phosphorus concentration $\left(\mathrm{P}_{\mathrm{p}}\right)$ and its fractional excretion $\left(\mathrm{FE}_{\mathrm{p}}\right)$ using the following formula [12]:

$$
P_{p} \cdot\left(1-F E_{p}\right)
$$

The two-tailed Mann-Whitney $U$ test and simple regressions with the rank correlation coefficient $\left(r_{s}\right)$ were used for statistical analysis. Values were expressed either as individual data or as 25 th percentile, median and 75 th percentile. A $P<0.05$ was regarded as statistical significant $[13,14]$.

\section{Results}

The 14 Gitelman's patients and the 14 control subjects did not significantly differ with respect to height, dietary intake of sodium, calcium or magnesium, blood pressure and heart rate, packed cell volume, plasma creatinine and sodium, plasma and urinary uric acid, as well as plasma inorganic phosphorus and tubular phosphorus threshold (Table 1). Apart from the biochemical hallmarks of Gitelman's syndrome, namely alkalaemia, hyperbicarbonataemia, hypokalaemia, hypomagnesaemia, increased urinary chloride over creatinine ratio, increased urinary magnesium over creatinine ratio, and low urinary calcium over creatinine ratio, the patients were found to have hyperproteinaemia, hypochloraemia (and high fractional chloride excretion), high total plasma calcium concentration, reduced plasma ionized calcium concentration, and high urinary sodium excretion (Table 1 and Figure 1 ). The body weight tended to be reduced in patients.

In Gitelman's patients the increased urinary magnesium over creatinine ratio was associated with an increased fractional magnesium clearance and with an increased magnesium excretion corrected for GFR. The reduced urinary calcium over creatinine ratio was associated with low apparent fractional calcium clearance, low true fractional calcium clearance and low calcium excretion corrected for GFR. The reduced urinary calcium over creatinine ratio was associated with low apparent fractional calcium clearance, low true fractional calcium clearance and low calcium excretion corrected for GFR (Table 1 and Figure 1).

The urinary osmolality after overnight water deprivation (Table 2) was slightly but significantly lower in patients (ranges $526-1067 \mathrm{mmol} / \mathrm{kg}$ ) than in controls (ranges $752-1221 \mathrm{mmol} / \mathrm{kg}$ ). Total protein excretion, glucosuria, and aminoaciduria were almost identical in patients and controls (Table 2).

In Gitelman's patients a statistically significant relationship (Figure 2, panel 1) was observed between plasma magnesium, taken as independent variable, and magnesium excretion corrected for GFR, taken as dependent variable $\left(y=77.1-78.5 x ; \quad r_{s}=0.79\right.$; $P<0.01)$. In control subjects the two parameters did not correlate. No significant correlation was found between circulating magnesium or urinary magnesium excretion corrected for GFR and urinary calcium or potassium excretion corrected for GFR in patients and controls (Figure 2, panels 1-3). In both study groups no significant correlation was observed between blood $\mathrm{pH}$ or plasma bicarbonate and urinary magnesium, calcium or potassium excretion corrected for GFR (Figure 2, panels 5-7, 9-11). Finally, in both groups no significant correlation was found between urinary magnesium and urinary potassium excretion corrected for GFR (Figure 2, panel 8) or between urinary sodium and urinary calcium excretion corrected for GFR (Figure 2, panel 12).

\section{Discussion}

The present investigation was performed in children and adolescents with Gitelman's syndrome, the hypocalciurica variant of Bartter's syndrome [1-9]. The study provides information on three phenomena, one dealing with the mechanisms underlying magnesium deficiency, one dealing with the mechanisms underlying hypocalciuria, and one dealing with the site of the renal tubular dysfunction. 
Table 1. Clinical and biochemical findings in 14 patients with Gitelman's syndrome (aged 14-21 years) and 14 control subjects (aged 14-20 years); data as 25 th percentile, median, and 75 th percentile

\begin{tabular}{|c|c|c|}
\hline & $\begin{array}{l}\text { Patients with } \\
\text { Gitelman syndrome }\end{array}$ & $\begin{array}{l}\text { Control } \\
\text { subjects }\end{array}$ \\
\hline Body weight (kg) & $32.8-45.0^{*}-56.1$ & $50.8-56.5-63.3$ \\
\hline Height $(\mathrm{m})$ & $1.42-1.54-1.66$ & $1.63-1.67-1.75$ \\
\hline Supine blood pressure ( $\mathrm{mmHg}$ ) & $104-111-115 / 66-69-73$ & $108-110-118 / 68-70-74$ \\
\hline Supine heart rate (beats/min) & $70-73-77$ & $70-73-80$ \\
\hline Packed cell volume & $0.40-0.44-0.47$ & $0.40-0.42-0.45$ \\
\hline Plasma creatinine $(\mu \mathrm{mol} / \mathrm{l})$ & $63-71-81$ & $75-77-80$ \\
\hline Total plasma protein $(\mathrm{g} / \mathrm{l})$ & $76.0-78.2^{*}-80.4$ & $71.8-73.4-75.6$ \\
\hline Blood pH & $7.41-7.43 \dagger-7.44$ & $7.32-7.33-7.35$ \\
\hline Plasma bicarbonate $(\mathrm{mmol} / \mathrm{l})$ & $31.0-31.6+-32.2$ & $25.7-27.4-29.2$ \\
\hline \multicolumn{3}{|l|}{ Inorganic phosphorus } \\
\hline plasma concentration $(\mathrm{mmol} / 1)$ & $1.13-1.23-1.42$ & $1.19-1.24-1.30$ \\
\hline tubular threshold $(\mathrm{mmol} / \mathrm{l})$ & $1.05-1.08-1.17$ & $1.08-1.16-1.21$ \\
\hline \multicolumn{3}{|l|}{ Uric acid } \\
\hline total plasma concentration $(\mu \mathrm{mol} / \mathrm{l})$ & $208-247-329$ & $193-216-234$ \\
\hline fractional clearance $\left(10^{-2}\right)$ & $6.61-8.93-12.3$ & $6.35-7.47-9.76$ \\
\hline excretion $(\mu \mathrm{mol} / \mathrm{l} \mathrm{GFR})$ & $17.9-22.2-27.2$ & $14.7-17.0-18.2$ \\
\hline \multicolumn{3}{|l|}{ Potassium } \\
\hline plasma concentration $(\mathrm{mmol} / \mathrm{l})$ & $2.8-2.9 \dagger-2.9$ & $4.2-4.3-4.4$ \\
\hline urinary potassium over creatinine & $4.64-6.02^{*}-10.4$ & $2.33-3.66-5.70$ \\
\hline fractional clearance $\left(10^{-2}\right)$ & $14.7-15.37-22.6$ & $4.90-7.14-10.3$ \\
\hline excretion $(\mu \mathrm{mol} / 1$ GFR) & $390-462 *-728$ & $208-303-435$ \\
\hline \multicolumn{3}{|l|}{ Chloride } \\
\hline plasma concentration $(\mathrm{mmol} / \mathrm{l})$ & $94.3-96.09-101$ & $103-104-105$ \\
\hline urinary chloride over creatinine & $14.6-17.2 \dagger-25.6$ & $5.3-9.3-14.6$ \\
\hline fractional clearance $\left(10^{-2}\right)$ & $1.10-1.319-1.91$ & $0.35-0.77-1.07$ \\
\hline excretion $(\mu \mathrm{mol} / \mathrm{l} \mathrm{GFR})$ & $1035-1229^{*}-18202$ & $359-805-1124$ \\
\hline \multicolumn{3}{|l|}{ Sodium } \\
\hline dietary intake (mmol/day) & $122-190-267$ & $133-207-268$ \\
\hline . urinary sodium over creatinine & $10.8-17.3^{*}-25.4$ & $3.97-7.02-12.8$ \\
\hline plasma concentration $(\mathrm{mmol} / \mathrm{l})$ & $138-140-141$ & $140-142-143$ \\
\hline fractional clearance $\left(10^{-2}\right)$ & $0.58-0.89^{*}-1.23$ & $0.19-0.40-0.78$ \\
\hline excretion $(\mu \mathrm{mol} / 1 \mathrm{GFR})$ & $803-1236^{*}-1716$ & $271-565-1115$ \\
\hline \multicolumn{3}{|l|}{ Magnesium } \\
\hline dietary intake (mmol/day) & $8.1-10.1-13.5$ & $9.3-10.2-13.6$ \\
\hline total plasma concentration $(\mathrm{mmol} / \mathrm{l})$ & $0.49-0.55 \dagger-0.64$ & $0.78-0.81-0.89$ \\
\hline urinary magnesium over creatinine & $0.384-0.475 \dagger-0.582$ & $0.141-0.165-0.219$ \\
\hline fractional clearance $\left(10^{-2}\right)$ & $3.96-5.234-8.41$ & $1.40-1.66-1.82$ \\
\hline excretion $(\mu \mathrm{mol} / 1$ GFR $)$ & $23.9-29.11-44.5$ & $10.3-14.0-15.4$ \\
\hline \multicolumn{3}{|l|}{ Calcium } \\
\hline dietary intake ( $\mathrm{mmol} / \mathrm{day})$ & $14.5-16.1-18.2$ & $11.0-15.5-21.1$ \\
\hline total plasma concentration $(\mathrm{mmol} / \mathrm{l})$ & $2.45-2.51^{*}-2.56$ & $2.33-2.39-2.42$ \\
\hline ionized plasma concentration $(\mathrm{mmol} / \mathrm{l})$ & $1.24-1.27^{*}-1.32$ & $1.31-1.33-1.34$ \\
\hline urinary calcium over creatinine & $0.0130-0.0240 \dagger-0.0373$ & $0.179-0.242-0.288$ \\
\hline apparent fractional clearance $\left(10^{-2}\right)$ & $0.0313-0.0716-0.102$ & $0.617-0.788-1.01$ \\
\hline true fractional clearance $\left(10^{-\hat{2}}\right)$ & $0.0629-0.1429-0.209$ & $1.10-1.42-1.82$ \\
\hline excretion $(\mu \mathrm{mol} / \mathrm{l}$ GFR) & $0.779-1.819-2.69$ & $14.6-19.3-24.1$ \\
\hline
\end{tabular}

$\dagger$ Patients and controls were not compared with respect to this parameter (a statistically significant difference is predictable as the parameter had to be abnormal for the subjects to be included in the group of patients). ${ }^{*} P<0.05$ and $\uparrow P<0.01$ versus control group.

\section{Mechanisms underlying hypomagnesaemia}

When magnesium intake is restricted or when its intestinal absorption is altered, the kidney avidly retains magnesium [15-17]. In our patients with hypomagnesaemia the urinary magnesium excretion was higher than in healthy controls. This fact, together with the observed correlation between plasma magnesium and urinary magnesium excretion corrected for GFR, demonstrates the renal origin of magnesium wasting. Blood $\mathrm{pH}$ and plasma bicarbonate may modulate the urinary magnesium excretion [15-17], but in this study no correlation was found between blood hydrogen ion level or plasma bicarbonate and urinary magnesium excretion corrected for GFR. Dietary magnesium was similar in Gitelman's patients and in controls. On the contrary, the urinary magnesium excretion was higher in Gitelman's patients than in controls. Taken together these data point to high intestinal magnesium absorption as a compensation for renal loss of magnesium in Gitelman's patients.

\section{Mechanisms underlying hyocalciuria}

High total plasma calcium concentration but low ionized plasma calcium concentration were observed in our patients with Gitelman's syndrome. Calcium in body fluids exists in three forms, namely the form 
Total Plasma

Calcium, mmol/l lonized Plasma

Calcium, mmol/l

\section{Molar Urinary \\ Calcium to}

Creatinine
Apparent Fractional
Calcium Clearance

True Fractional

Calcium Clearance
Calciuria Corrected for GFR, $\mu \mathrm{mol} / /$ GFR

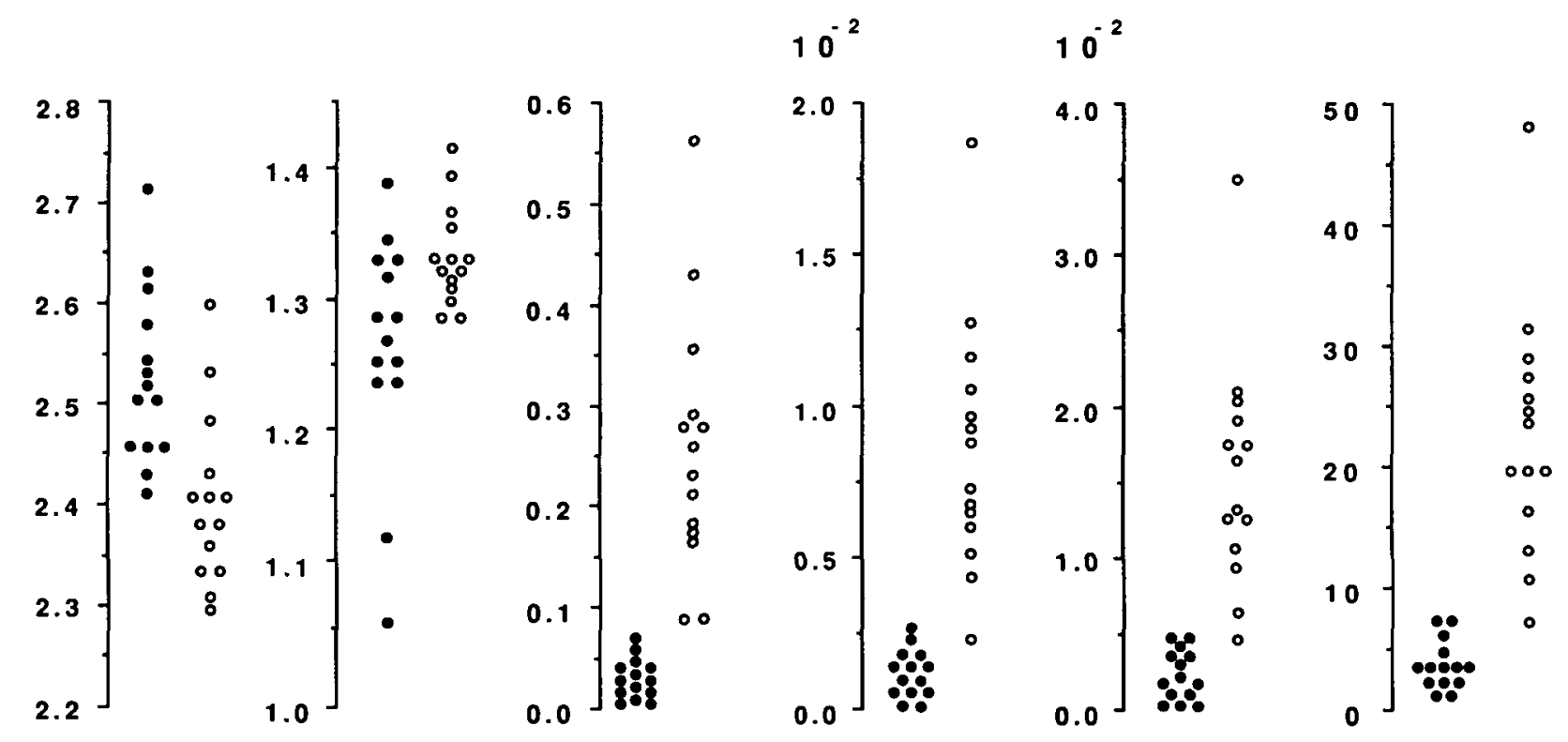

Fig. 1. Total plasma calcium, plasma ionized calcium, molar urinary calcium over creatinine, apparent fractional calcium clearance, true fractional calcium clearance, and calcium excretion corrected for GFR in 14 patients with Gitelman's syndrome (black symbols) and 14 control subjects (open symbols).

Table 2. Urinary osmolality, proteinuria, glucosuria, and aminoaciduria in 14 patients with Gitelman's syndrome aged $14-21$ years, and 14 control subjects aged $14-20$ years; data as 25 th percentile, median, and 75 th percentile

\begin{tabular}{|c|c|c|}
\hline & $\begin{array}{l}\text { Patients with } \\
\text { Gitelman syndrome }\end{array}$ & $\begin{array}{l}\text { Control } \\
\text { subjects }\end{array}$ \\
\hline Urinary osmolality (mmol/kg) & $626-6999-749$ & $931-977-1104$ \\
\hline Protein over creatinine $(\mathrm{mg} / \mathrm{mmol})$ & $5.6-7.8-14$ & $5.2-8.3-12$ \\
\hline Glucose $(\mathrm{mmol} / \mathrm{l})$ & $0.28-0.79-1.2$ & $0.39-0.64-0.97$ \\
\hline Alanine over creatinine $\left(10^{-3}\right)$ & $25-42-55$ & $29-50-59$ \\
\hline Arginine over creatinine $\left(10^{-3}\right)$ & $2-4-5$ & $2-4-5$ \\
\hline $1 / 2$ Cystine over creatinine $\left(10^{-3}\right)$ & $1-10-15$ & $8-11-23$ \\
\hline Glutamic acid over creatinine $\left(10^{-3}\right)$ & $11-18-20$ & $8-15-20$ \\
\hline Glycine over creatinine $\left(10^{-3}\right)$ & $87-158-222$ & $57-144-214$ \\
\hline Histidine over creatinine $\left(10^{-3}\right)$ & $38-84-125$ & $33-58-108$ \\
\hline Isoleucine over creatinine $\left(10^{-3}\right)$ & $1-2-5$ & $1-4-5$ \\
\hline Leucine over creatinine $\left(10^{-3}\right)$ & $1-4-5$ & $1-2-7$ \\
\hline Lysine over creatinine $\left(10^{-3}\right)$ & $29-35-46$ & $34-43-48$ \\
\hline Methionine over creatinine $\left(10^{-3}\right)$ & $1-2-3$ & $1-2-3$ \\
\hline Ornithine over creatinine $\left(10^{-3}\right)$ & $1-4-6$ & $4-5-6$ \\
\hline Phenylalanine over creatinine $\left(10^{-3}\right)$ & $7-9-12$ & $5-7-10$ \\
\hline Proline over creatinine $\left(10^{-3}\right)$ & $1-4-7$ & $2-5-7$ \\
\hline Serine over creatinine $\left(10^{-3}\right)$ & $23-38-55$ & $23-32-55$ \\
\hline Taurine over creatinine $\left(10^{-3}\right)$ & $34-44-67$ & $30-44-70$ \\
\hline Threonine over creatinine $\left(10^{-3}\right)$ & $10-21-36$ & $11-19-35$ \\
\hline Tyrosine over creatinine $\left(10^{-3}\right)$ & $15-17-21$ & $10-15-21$ \\
\hline Valine over creatinine $\left(10^{-3}\right)$ & $2-6-7$ & $1-4-8$ \\
\hline
\end{tabular}

ף $P<0.05$ versus control group.

The aminoaciduria is given as molar ratio over creatinine.

bound to proteins, the form complexed with lowmolecular-weight anions such as bicarbonate, and the free or ionized form, the only form biologically active [18]. Plasma ionized calcium concentration appears therefore dependent on several factors. The amount of circulating calcium bound to proteins or complexed to bicarbonate increases with a decline in hydrogen ion concentration and with an increase in plasma bicarbonate or proteins: these facts account for the discrepancy between high total and low ionized calcium concentration in our group of Gitelman's patients presenting with hyperbicarbonataemia, alkalaemia, and hyper- 

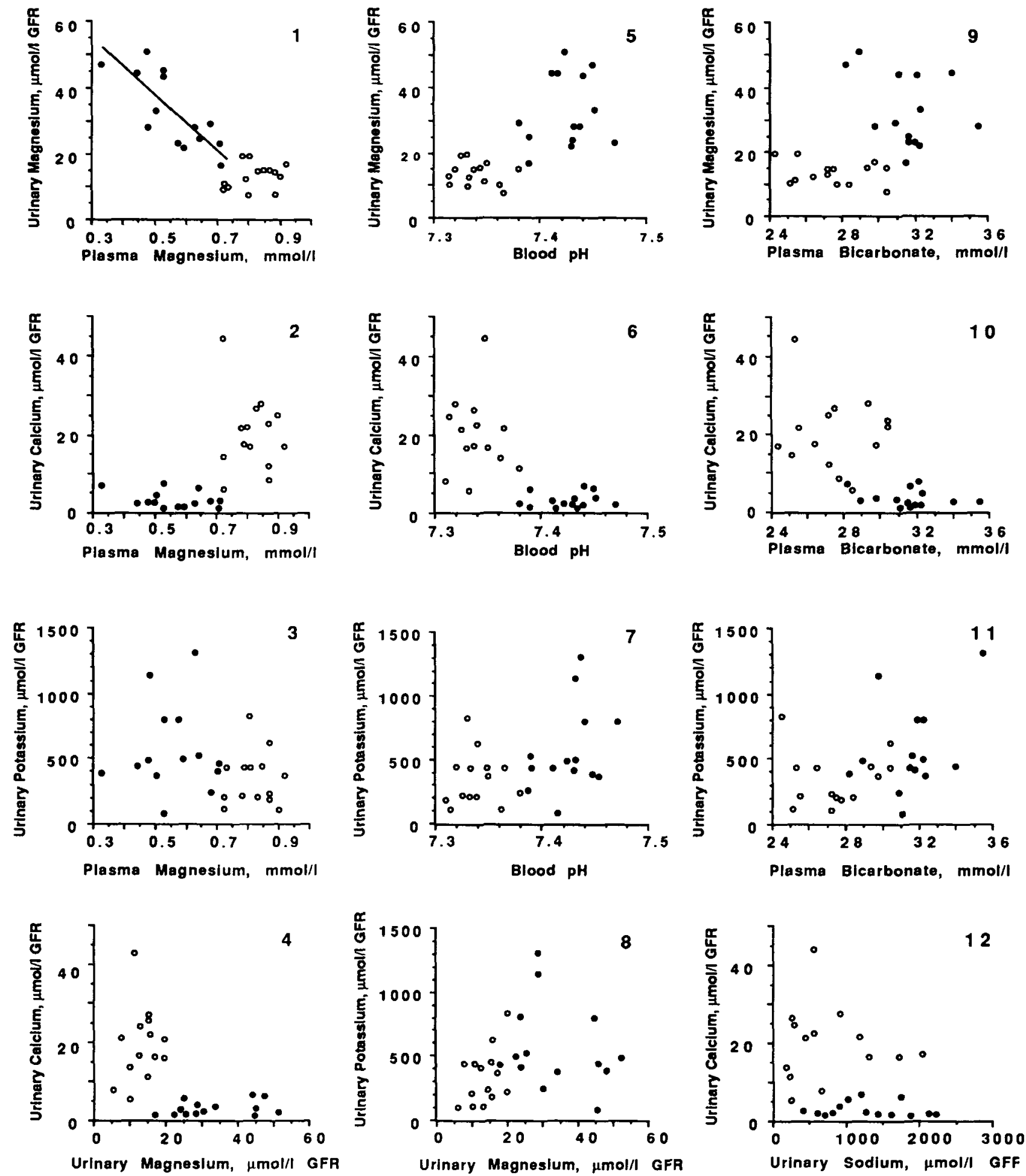

Fig. 2. Relationship between plasma magnesium and urinary magnesium excretion corrected for GFR (panel 1), between plasma magnesium and urinary calcium excretion corrected for GFR (panel 2), between plasma magnesium and urinary potassium excretion corrected for GFR (panel 3), between urinary magnesium excretion corrected for GFR and urinary calcium excretion corrected for GFR (panel 4), between blood $\mathrm{pH}$ and urinary magnesium excretion corrected for GFR (panel 5), between blood pH and urinary calcium excretion corrected for GFR (panel 6), between blood pH and urinary potassium excretion corrected for GFR (panel 7), between urinary magnesium excretion corrected for GFR and urinary potassium excretion corrected for GFR (panel 8), between plasma bicarbonate and urinary magnesium excretion corrected for GFR (panel 9), between plasma bicarbonate and urinary calcium excretion corrected for GFR (panel 10), between plasma bicarbonate and urinary potassium excretion corrected for GFR (panel 11), between urinary sodium excretion corrected for GFR and urinary calcium excretion corrected for GFR (panel 12) in 14 patients with Gitelman's syndrome (black symbols) and 14 control subjects (open symbols). In patients a significant $(P<0.05)$ relationship was observed between circulating and urinary magnesium $\left(y=77.1-78.5 x ; \mathrm{r}_{\mathrm{s}}=0.79 ; P<0.01\right.$; panel 1$)$. 
proteinaemia. The tendency towards hypocalcaemia observed in our patients with Gitelman's syndrome is probably the consequence of a blunted secretion of parathyroid hormone induced by hypomagnesaemia [15-17,19].

Severe hypocalciuria, expressed either as calcium over creatinine ratio, as apparent or true fractional calcium clearance, or as calcium excretion corrected for GFR, is the most striking feature in Gitelman's syndrome. The results of dietary records indicate that in our patients hypocalciuria does not result from low dietary calcium intake. Dietary sodium intake modulates the urinary calcium excretion but in this study we found a similar dietary salt intake in patients and controls without any correlation between excretion of calcium and sodium. Finally, in Gitelman's syndrome hypocalciuria may be related only in part to mild concomitant hypocalcaemia, since both the true fractional calcium clearance and the calcium excretion corrected for GFR were low, indicating avid tubular reabsorption. Hypomagnesaemia promotes tubular calcium reabsorption [15-17]. For that reason it has been suggested that hypocalciuria in Gitelman's syndrome may be secondary to hypomagnesaemia, but in our patients no correlation was found between urinary calcium excretion corrected for GFR and urinary magnesium excretion corrected for GFR or plasma magnesium. Data from the literature indicate that in Gitelman's syndrome urinary calcium excretion remains low even after correction of magnesium deficiency [4]. This fact and our observations suggest that in Gitelman's syndrome hypomagnesaemia is not the cause of hypocalciuria. Whatever the underlying mechanisms, increased tubular reabsorption of calcium appears a diagnostic sine qua non for this variant of Bartter's syndrome [1-9].

\section{Site of the tubular defect in Gitelman's syndrome}

The present study provides information on the proximal tubular function and on the ability to concentrate urine in Gitelman's syndrome. A proximal tubular defect has been sometimes reported in patients with Bartter's syndrome [20]. In our Gitelman's patients the failure to demonstrate excessive urinary excretion of amino acids, glucose, phosphorus, and uric acid suggests a normal proximal tubular function [21-23]. In Gitelman's patients the urinary osmolality after overnight fasting was always higher than $526 \mathrm{mmol} / \mathrm{kg}$. This fact provides evidence against a disturbance residing in the loop or in the collecting tubule [24,25]. The slightly reduced urinary osmolality observed in Gitelman's patients as compared with controls is probably related to the concomitant potassium depletion [24,25].

The laboratory features of Gitelman's syndrome resemble those induced by thiazides, which bind to and inhibit the luminal sodium-chloride cotransporter in the distal convoluted tubule [3-5,7]. A blunted response to thiazides has been reported in adult patients with this tubulopathy [4]. Taken together, the results of the present investigation and the aforementioned observations indicate that Gitelman's syndrome appears best explained by a defective sodium-chloride carrier protein along the distal convoluted tubule. However, the primary tubular abnormality and the events underlying the characteristic biochemical disturbances of Gitelman's syndrome are still incompletely understood. Molecular biology studies are required to definitely answer this question.

\section{Conclusion}

The present study on Gitelman's syndrome demonstrates the renal origin of magnesium deficiency and hypocalciuria and provide some evidence for a defect residing in the distal convoluted tubule.

\section{References}

1. Gitelman HJ, Graham JB, Welt LG. A new familial disorder characterized by hypokalemia and hypomagnesemia. Trans Assoc Am Physicians 1966; 79: 221-235

2. McCredie DA, Blair-West JR, Scoggins BA, Shipman R. Potassium-losing nephropathy of childhood. Med J Austr 1971; 1: $129-135$

3. Bettinell A, Bianchetti MG, Girardin E et al. Use of calcium excretion values to distinguish two forms of primary renal tubular hypokalemic alkalosis: Bartter and Gitelman syndromes. $J$ Pediatr 1992; 120: 38-43

4. Sutton RAL, Mavichak V, Halabe A, Wilkins GE. Bartter's syndrome: evidence suggesting a distal tubular defect in a hypocalciuric variant of the syndrome. Miner Electrolyte Metab 1992; 18: 43-51

5. Rodríguez-Soriano J, Vallo A, García-Fuentes M Hypomagnesemia of hereditary renal origin. Pediatr Nephrol 1987; 1: 465-472

6. Pistor K, Heemann K, Olbing H. Asymptomatische Hypokaliämie und Hypomagnesiämie mit renalem Kationenverlust (Gitelman-Syndrom). Monatsschr Kinderheilkd 1987; 135: 340-342

7. Colussi G, Rombolà G, De Ferrari ME. Distal nephron function in familial hypokalemia-hypomagnesemia (Gitelman's syndrome). Nephron 1994; 66: 122-123

8. Seyberth HW. How can you differentiate neonatal Bartter's syndrome from hyperprostagland (-uria) $\mathrm{E}_{2}$ syndrome. Pediatr Nephrol 1994; 8: 407

9. Bettinelli A, Bianchetti MG, Borella $\mathrm{P}$ et al. Genetic heterogeneity in tubular hypomagnesemia-hypokalemia with hypocalciuria (Gitelman's syndrome). Kidney Int 1995; 47: 547-551

10. Donati R, Donati-Genet P, Peheim E, Bianchettı MG. Dietary sodium or protein and calciuria in children and adolescents. $J$ Nephrol 1994; 7: 280-283

11. Bianchetti MG, Kanaka C, Ridolfi-Lüthy A, Hirt A, Wagner HP, Oetliker $O H$. Persisting renal tubular sequelae after cisplatin in children and adolescents. Am J Nephrol 1991; 11: 127-130

12. Alon U, Hellerstein A. Assessment and interpretation of the tubular threshold for phosphate in infants and children. Pediatr Nephrol 1994; 8: 250-251

13. Brown GW, Hayden GF. Nonparametric methods. Clin Pediatr 1985; 24: 590-598

14. Broen RA, Beck IS. Statistics on microcomputers. A nonalgebric guide to their appropriate use in biomedical research and pathology laboratory practice: 1 . data handling and preliminary analysis. J Clin Pathol 1998; 41: 1033-1038

15. Dirk JH. The kidney and magnesium regulation. Kidney Int 1983; 23: 771-777

16. Elin RJ. Magnesium metabolism in health and disease. Dis Mon 1988; 34: $164-218$ 
17. Rude RK. Magnesium metabolism and deficiency. Endocrinol Metab Clin North Am 1993; 22: 377-395

18. Mallette LE. Regulation of blood calcium in humans. Endocrinol Metab Clin North Am 1989; 8: 601-610

19. Bianchetti MG, Bettinelli A, Casez JP et al. Evidence for disturbed regulation of calciotropic hormone metabolism in Gitelman syndrome. J Clin Endocrinol Metab 1995; 80: 224-228

20. Rodriguez-Soriano J, Vallo A, Oliveros R. Bartter's syndrome presenting with features resembling renal tubular acidosis. Improvement of renal tubular defects by indomethacin. Helv Paediatr Acta 1978; 33: 141-151
21. Burg MB. The Nephron in transport of sodium, amino acids, and glucose. Hosp Pract 1978; 13: 99-109

22. Holmes EW, Kelley WN, Wyngaarden JB. The kidney and uric acid excretion in man. Kidney Int 1972: 2: 115-118

23. Cogan MG. Disorders of proximal nephron function. Am J Med 1982; 72: 275-288

24. Kokko JP. Renal concentrating and diluting mechanisms. Hosp Pract 1979; 14: 110-116

25. Rouffignac $C$. Physiological role of the loop of Henle in urinary concentration. Kidney Int 1972; 2: 297-303 